\title{
Energy Efficiency Analysis of Trawlers (Case Study: Indonesian’s Trawler)
}

\author{
Alyuan Dasira $^{1}$ and J.M Laurens ${ }^{2}$
}

\begin{abstract}
Nowadays, the energy efficiency is of most importance in all economical activities. For the fishing industry, it is particularly critical. Energy efficiency in the fishing sector can be expressed in term of the ratio of fishing capture over operational cost. The fuel cost in ship operation became a dominant factor of the total operational cost. Moreover, fuel cost is high and continues to increase. One way to achieve better energy efficiency is to use a high efficiency ship propeller in order to diminish fuel consumption. Trawlers have two main operational conditions; they are the voyage condition and the trawling condition. The voyage condition is when the trawler travels to port and to the fishing grounds. The trawling condition is when the trawler pulls the trawl to catch fish. Most of trawler problem is in trawling operation with trawls, the ship resistance increased tremendously and then the propeller must work harder to ensure the ship can advance against the trawling resistance at low speed, 3, 5 Knots. This condition corresponds to a heavy load condition. In this condition, the propeller efficiency is low. Duct propeller is one of the configurations that increase the propeller efficiency in heavy loaded condition. The other strategy is to increase the energy efficiency is to optimize ship speed in voyage condition. In this research, the numerical simulations performed for the propeller-duct interactions were made possible thank to an iterative procedure where the flow around each of the several components are modeled with a potential flow theory. Boundary element Method (BEM) or panel method is used to solve the potential flow model. The models and methods are described in the document as well as the iterative procedure that has been developed within the framework of this project. We have investigated energy efficiency with fuel consumption approach. Propeller with and without duct in same size (B3-65 and Kaplan 65 in Duct 19A) are analyzed and optimized ship speed 9 Knots to 7 Knots. It shows that $13.7 \%$ of the fuel consumption was saved with a duct propeller in trawling condition and $35 \%$ of the fuel consumption was saved with an optimized ship speed in voyage condition.
\end{abstract}

Keywords—energy efficiency; trawlers (fishing ship); ducted propeller; boundary element method; potential flow.

\section{INTRODUCTION}

$\mathrm{N}$ owadays, the energy efficiency is of upmost importance in all economical activities. The fishing industry is particularly affected. As known, the total world exports of fish and fish products reached a record value of US\$200 billion [1]. Fishing is a dominant economic factor in the country which has many islands and which mainly consists of coastal areas. Indonesia presents the second largest coastline in the world and has the advantage in his geographic condition to consist of $75 \%$ oceans for $25 \%$ of lands.

Generally, efficiency in terms of fishing can be expressed by the ratio of fishing capture over the operational cost. The fuel cost now reached some critical value and is still increasing. In operational cost, fuel consumption is a dominant factor of the total operational cost. Thus, energy efficiency can be investigated by using fuel consumption approach. It is possible to evaluate performance of trawler under different operating conditions. The fuel consumption is mainly due to the propulsion system. Using a better propeller increases the energy efficiency. Moreover, a better efficiency can decrease the pollution due to fishing activities.

Trawlers operate in two main conditions, the voyage condition and the trawling condition. In each condition, the propeller plays an important role to determine whether the fishing vessel presents a good efficiency or not. The trawling condition is the condition in which the fishing boat pulls the trawl to catch fish. In this

\footnotetext{
${ }^{1}$ Alyuan Dasira is with Departement of Marine Engineering, Faculty of Marine Engineering, Institut Teknologi Sepuluh Nopember, Surabaya, 60111, Indonesia. E-mail: alyuan_d@yahoo.co.id.

${ }^{2}$ J.M Laurens is with Departement of Naval architecture and Marine engineering, ENSTA Bretagne, Brest, France. E-mail: jeanmarc.laurens@ensta-bretagne.fr.
}

condition, the ship operates at low velocity. The problem is when a ship operates with a trawl, the ship resistance increases and the propeller must work harder to ensure that the ship can advance against that additional resistance. The resistance of the trawl can reach 90-95\% of the total resistance. It depends on the type of trawls. The propeller is then very highly loaded and as a result, its efficiency is low. Thus, much of the energy is wasted. Duct propeller is one tool to increase the propeller efficiency in heavy loaded conditions. The duct then participates to the thrust and its contribution can reach $50 \%$ of the total thrust. This is particularly advantageous for tugs propulsion or dynamic positioning thrusters which often work near bollard pull condition [2]. It is a solution for efficiency problem in trawling condition.

Because of the two operational conditions, voyage and trawling, another problem appears when the propeller type has been chosen only according to the trawling condition only; there is a chance for the propeller to be a bad choice for the other operational condition, the voyage condition. Moreover, the choice of the ship speed for the voyage condition can be a problem when the power required in voyage condition is not similar to the trawling condition. Large difference in the power required between both conditions must be avoided when using a diesel engine to ensure that there are not waste of energy and/or damage to the engine. Thus, we must optimize the ship velocity in voyage condition to match the power required in trawling condition. This solution can be considered if the sailing time does not affect the fishing boat efficiency or the fish value. On the other hand, the fuel consumption depends on the velocity of the ship. The higher the velocity, the higher is the fuel consumption. It can be seen in the graphic of Figure 1, which presents the fuel consumption versus ship speed for various propeller pitches. The relation is not linear. The voyage velocity must be optimized according to the 
fuel consumption in voyage condition but respecting the power required in trawling condition. Once the power and the RPM have been fixed, the only adjustable variable is the propeller pitch. All the curves of Figure 1 are given for the same RPM, only the propeller pitch varies. That explains why most trawlers have a variable pitch propeller.

The present study addresses the optimization of trawler efficiency in both of conditions with ducted propeller analyzed in trawling condition and optimization ship speed in voyage condition. An Indonesian trawler has been considered in this research to analyze the achieved energy efficiency gain comparing the existing trawler efficiency and the potential efficiency obtained by calculation with various configurations.

\section{METHOD}

$\begin{array}{lll}\text { A. } & \text { Main Ship Data } & \\ \text { a. Name of ship } & \text { : KM Soerya } 87 \\ \text { b. } & \text { Ship type : Trawler (fishing ship) } \\ \text { c. Length of ship } & : 22,56 \text { meter } \\ \text { d. } & \text { Breadth } & : 7,79 \text { meter } \\ \text { e. Draft } & : 4.26 \text { meter } \\ \text { f. Ship velocity } & : 9 \text { knots } \\ \text { g. Ship bottom form : V } & \\ \text { h. } & \text { Main propulsion } & : \text { Diesel engine } \quad \text { (Caterpillar } \\ & \text { 3408TA) } & : 300 \mathrm{Kw} \\ \text { i. } & \text { Power } & : 1800 \mathrm{RPM} \\ \text { j. } & \text { RPM } & : 4: 1 \\ \text { k. } & \text { Reduction Ratio } & : 1.25 \mathrm{~m} \\ \text { l. } & \text { Prop diameter } & : 1 \\ \text { m. } & \text { Num of propeller } & : 3 \\ \text { n. } & \text { Num of blade } & \end{array}$

\section{B. Ship Resistance}

In Figure 2 the chart shows that the procedure starts with the calculation of the ship resistance. In order to find the characteristics of the ship propulsion and resistance in this case, firstly, the ship must be redrawn using the known parameters. The ranges for the parameters at this stage are: $\mathrm{Cb}(\mathrm{Lwl})=0.53-0.62$, $\mathrm{Lwl} / \mathrm{Bwl}=2.6-4.0 \mathrm{Bwl} / \mathrm{T}=2.0-3.0 \mathrm{Lwl} / \mathrm{Vol} 1 / 3=3.0-$ 4.5 and Froude Number $(\mathrm{Lwl})=0.2-0.43$. After that, the ship resistance can be estimated with hydrodynamic computation software code, Navcad (C). It uses the ship dimension (length, breadth, draft, coefficient block, prismatic coefficient, etc). To obtain all the necessary parameters, the ship hull is redrawn in Rhino (C), Figure 3

The resistance calculation is based on the UBC method analysis. UBC trawler analysis is based on the papers which published "Model Resistance Tests of a Systematic Series of Low L/B Vessels" and "Resistance Study on a Systematic Series of Low L/B Vessels. The results are presented in Figure 4.

In this case, the total resistance includes the trawl resistance at the trawling velocity, 3.5 knots. In this condition, 95\% of the resistance is due to the trawl and $5 \%$ to the bare ship resistance (Rbare). Reference [4] was used to determine the resistance components in trawling condition.

\section{Open water test diagram}

Open water propeller performances are used as a starting point. They give the propeller hydrodynamic performances without the ship hull interaction. There are several methods to generate the open water test diagram such as numeric simulation, experiment, etc. NavierStokes solver is an affordable numerical tool to simulate ducted propeller performances, but the quality of the mesh is critical and it still requires man-hours with expert's skill. There is a simpler model, Boundary Element Method (BEM) code or panel method code to solve hydrodynamic performances analysis in ducted propeller particularly [5]. In the panel method, the propeller is modeled as a thick body so is the duct. Moreover, the boundary element method only requires a surface mesh of the solid object. So, it needs a mesh generator for the propeller and for the duct. In this study, we use a fast mesh generator developed at Ensta Bretagne, [5]. In order to use the BEM code, first, we must generate the propeller and the duct geometries separately, see Figure 5. B-series data provide the main geometry data of each propeller type. In this study we use the B3-65 propeller and the Kaplan-65 (ducted propeller) geometries data [8].

Once the duct and the propeller meshes are generated, the next procedure is to calculate the hydrodynamic forces and coefficients. In this present study we use a BEM code. The calculation procedure in this study is an iterative computation to compute the interaction between the propeller and the duct. The procedure consists in separating the flow around the propeller and the flow around the duct into two different runs. Firstly, when the flow around the duct has been solved, we compute the duct induced velocities on the blades control points i.e. the centers of all the panels, see Figure 6

The details of the iterative procedure are illustrated in Figure 7. The flow around the propeller is then computed and the propeller induced velocities on the surface of the duct are calculated. The procedure is repeated until convergence which occurs after only a few iterations (Figure 8). The point of convergence shows the stable point in last iteration, and we can use this value in our analyzing. Figure 9 show the two types of propeller performances, bare propeller (represented by dashed lines) and ducted propeller (represented by solid lines). We can observe that the efficiency of the ducted propeller is better than for the bare propeller in heavy loaded condition i.e. when the advanced coefficient $J \in$ [0.1; 0.6] (Figure 9 Comparison KT KQ and eta for bare (--) and ducted (-) propeller). The additional thrust from the duct contributes to the propeller performance in this condition. On the other hand, the duct produces drag in the lightly loaded conditions; thus, in the lightly loaded conditions the ducted propeller shows a lower efficiency than the bare propeller.

It was explained in many papers such as [5] that the principle of the duct is to add more thrust than the loss of propeller thrust due to its presence which accelerate the flow. By applying the Bernoulli equation on a semiinfinite streamlines on each side of the actuator disk, we obtain that the ratio between the downstream wake and 
the upstream wake to be: $1+C_{\mathrm{Th}}$, where $C_{\mathrm{Th}}$ is the thrust loading coefficient defined as:

$C_{\mathrm{Th}}=\frac{T}{0.5 \rho \cdot V_{A}^{2} \cdot A_{p}}$

From this simple model, we therefore obtain the theoretical loss of efficiency due to kinetic energy in the wake. It gives the maximum efficiency $\eta$ for a bare propeller to be:

$\eta($ ideal $)=\frac{2}{1+\sqrt{1+C_{\mathrm{Th}}}}$

The same procedure also gives the maximum efficiency for a ducted propeller:

$\eta($ ideal $)=\frac{2}{1+\sqrt{1+\tau C_{\mathrm{Th}}}}$

Where, $\tau$ is the ratio of the additional thrust given by the duct $T_{D}$ over to total thrust $T_{T}$. This formula shows how a duct propeller can provide a better efficiency. When the propeller works in heavy load condition, $C_{\mathrm{Th}}$ can show a higher value. Using the formula (2), the ideal efficiency, $\eta$ (ideal), is decreasing with the $C_{\mathrm{Th}}$. The higher the $C_{\mathrm{Th}}$, the lower is the ideal efficiency. Using the ideal efficiency formula for ducted propeller (3) with the presence of $\tau$ (ratio), in similar condition, a better ideal efficiency can be obtained [7].

\section{Ship Efficiency Calculation}

In the present study, ship efficiency calculations comparing bare propeller and duct propeller is carried out. The calculations concern a fishing ship in realistic operational conditions. An existing ship is used and the ship dimensions are respected so are the propulsion characteristics, the engine characteristics, the operational condition, etc.

Once the engine characteristic curve is known, the next step is to generate the ship and the propeller characteristic curves. It is called the propeller load curve. The principle at this stage is to match the ship and the propeller loads. The propeller load is represented by the $K_{\mathrm{T}}$ curve and is generated by open water test simulations of the previous stage (

Figure 9 Comparison KT KQ and eta for bare (--) and ducted (-) propeller. To generate the ship load curves ( $K_{\mathrm{T}}$ ship), we must first use the $\beta=K_{\mathrm{T}} / J^{2}$ formula (5). Where, $\beta$ can be calculated using formula (4):

$\beta=\frac{\mathrm{T}}{\rho \mathrm{V}^{2} \mathrm{D}^{2}}$

When $\beta$ is known, we can generate the $\mathrm{K}_{\mathrm{T}}$ ship curves in relation with $J$ (the advanced coefficient).

$\mathrm{K}_{\mathrm{T}}$ ship $=\beta J^{2}$

There are two operation conditions; trawling and voyage conditions. Thus, in this present study, we generate two types of $K_{\mathrm{T}}$ ship curves as it is presented in Figure 10. In trawling condition, $K_{\mathrm{T}}$ ship shows heavy loaded behavior because the ship runs at low speed (3.5 knots) with a high resistance (trawl). In this condition, the ship is catching fish. Then, for the next step we plot the $K_{\mathrm{T}}$ ship curves onto the open water propeller results of

Figure 9 ( $K_{\mathrm{T}}$ propellers). In this manner, we find the crossing point between the $K_{T}$ ship and $K_{T}$ propellers (bare and ducted). We called these points, the reference points. These points indicate the advance parameter for the considered condition. By the reference points (crossing point of $K_{\mathrm{T}}$ ship and $K_{\mathrm{T}}$ propeller) we can determine the other variables $\left(K_{\mathrm{Q}}\right.$, eta and $\left.J\right)$. We used 2 types of propellers (bare and ducted), thus, we must determine the parameters $\left(K_{\mathrm{Q}}, \eta_{0}\right.$ and $\left.J\right)$ for each type of propeller. The procedure can be showed in Figure 11 . For each condition and each propeller type, we determine the intersection between the propeller thrust coefficient curve and the parabola drawn by the $K_{\mathrm{T}}$ ship.

By using these parameters values, the ship fuel consumption in each condition can be calculated. It can be calculated with the engine-propeller matching procedure. With this procedure, we can determine the BHP used by the engine for the corresponding propeller rotation. The fuel consumption is then given by multiplying the specific fuel oil consumption (sfoc) (g/kW-Hr) by the operating time (hour) and the BHP used $(\mathrm{Kw})$ or using fuel rate $(\mathrm{L} / \mathrm{hr})$ in engine curve. In the engine manual [10], we can know how much the sfoc is related to the engine RPM. The results of this stage are summarized in Table 1.

The Table 1 shows the percentage (\%) of saving in the fuel consumption using a ducted propeller (Kaplan propeller) compared to a bare propeller (B3-65). The results are given by different shares of the operating conditions (trawling and voyage time).

For the initial condition we decide that $40 \%$ of the time is spent trawling while $60 \%$ time is spent in the voyage. We claim in this case that $12.24 \%$ of fuel consumption saving is achieved when using a ducted propeller. But, if the ship has a flexible operational mode, the best saving is obtained when $50 \%$ of the time is spent trawling and $50 \%$ of the time is spent for the voyage. We obtain in this case, about $13.27 \%$ of fuel consumption saving. It indicates that by changing the mode of operation results in a significant fuel saving. By comparing with reference [6], the use of a duct propeller can reduce the power used up to $20 \%$ in heavy load propeller case. The present results are more practical, because we analyse the savings in terms of fuel consumption and not only in terms of power reduction. The fuel consumption depends also very much on the performance of the engine. The conclusion remains that a duct propeller consists of a good device to increase the propulsive efficiency of fishing ship particularly for trawlers.

\section{E. Optimizing Ship Velocity in Voyage Condition}

As in reference [7], we can also optimize the propulsive system for the voyage condition. It is a steaming speed operation. By using the similar analysis of the previous step, we can easily know why the steaming speed operation is an important option to optimize. Figure 12 illustrates the optimized BHP used for various ship velocities.

In order to calculate the percentage (\%) of the fuel consumption saving by optimizing the ship velocity, we use the comparison of the ship consumption for each ship velocity. The original voyage velocity is 9 knots but it presents a great different in BHP used than in trawling condition. We found that 7 knots would give the same BHP used than in trawling condition, see Figure 12. The result of calculation in saving fuel consumption for this analysis is presented in Table 1.

The Table 1 ship efficiency in speed optimize shows that the fuel consumption is reduced by $35.6 \%$ when using the optimized ship speed of 7 knots. By comparing with the results of reference [7], the results of the present study show an even larger saving. For the ship of reference [7], $18 \%$ fuel consumption saving was obtained by reducing the ship velocity from 10.25 knots to 9.75 knots. 


\section{RESULT AND DISCUSSION}

We have analysed the ship efficiency of a fishing vessel/trawler. Simulations using an iterative procedure between several BEM runs have been performed in order to compare a bare propeller and duct propeller performances. We found that for the same propeller diameter, using a duct propeller can increase the ship efficiency up to $13.7 \%$. We also have optimized the ship efficiency using an optimized velocity in voyage condition; we have obtained a fuel saving up to $35 \%$ by reducing ship speed operation from 9 to 7 knots. Many references presented theoretical efficiency using duct, but this present study focuses on the fuel savings which is a more practical approach.

\section{PERSPECTIVE}

This study showed that energy efficiency of trawler can be improved by using duct propeller and optimizing the ship speed. Ship efficiency in this present study can be calculated by using ship consumption approach. On the other hand, this approach can be adopted for all ship operational conditions, but it must take difficult to know the characteristic of fuel consumption in real condition. Because the ship runs in variable seas conditions and we need real data in real time (measured engine fuel consumption).Therefore, for future study, variable seas conditions can be included to obtain real time values. The ship design spiral for trawler must take into account the trawling condition because it can be a reference point

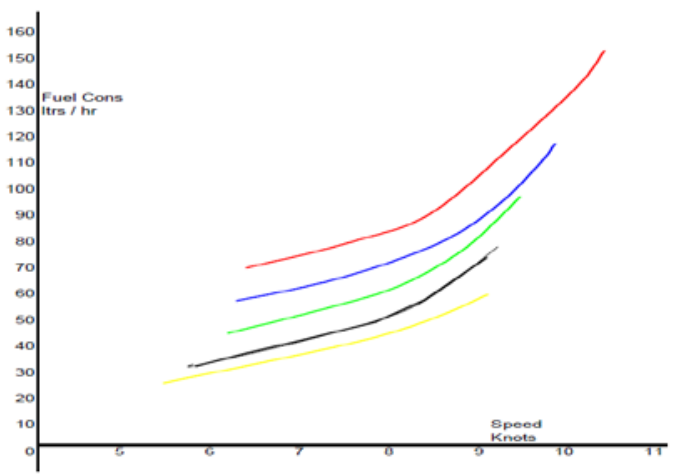

Figure 1. Fuel consumption (ton/days) versus ship speed (knots) for various values of the propeller pitch [3]

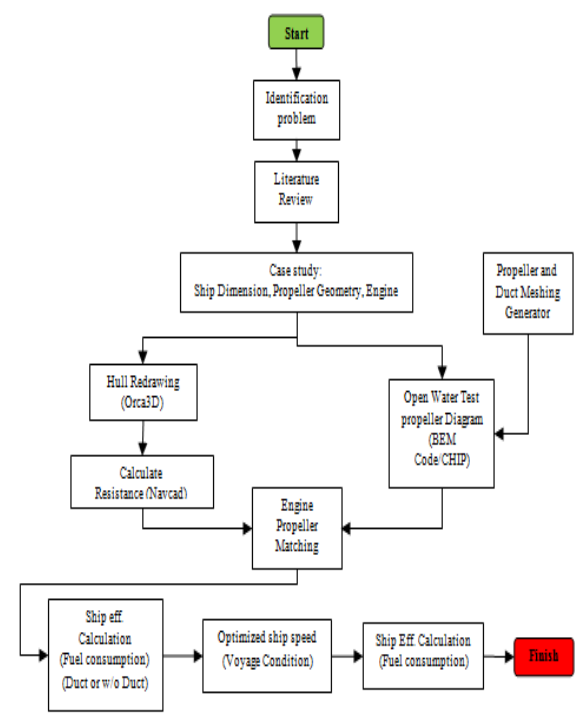

Figure 2. Computational flowchart procedures to decide on the ship velocity in voyage condition. Once our procedure totally validated, we intend to include a stator to obtain further fuel saving.

\section{REFERENCES}

[1]. United Nations Food and Agriculture Organization (FAO); the international fish trade and world fisheries, Fisheries and Aquaculture Department, June 2008.

[2]. El Lababidy, S.A., Bose, N., Liu, P., Walker, D.; Dynamic Positioning Thrusters Near Wake Hydrodynamic Characteristic at Near Bollard Pull, Journal of ship research, Vol.53, No1, March 2009.

[3]. Rihan, D., O'regan, Noel.,Deakin, Barry.; The Development of a "Green Trawler", First International Symposium on Fishing Vessel Energy Efficiency E-Fishing, Vigo, Spain, May 2010.

[4]. Balash, C., Sterling,D.; Prawn Trawl Drag Due To Material Properties, Second International Symposium on Fishing Vessel Energy Efficiency E-Fishing, Vigo, Spain, May 2012.

[5]. Laurens, J.-M., Moyne, S. and Deniset, F.; A BEM method for the hydrodynamic analysis of fishing boats propulsive systems, Second International Symposium On Fishing Vessel Energy Efficiency E-Fishing, Vigo, Spain, May 2012.

[6]. Notti, E., Sala, A.,; On the opportunity of improving propulsion system efficiency for italian fishing vessels, Second International Symposium on Fishing Vessel Energy Efficiency, E-Fishing, Vigo, Spain, May 2012.

[7]. Messina, G., Notti E.,; Energy saving in trawlers: practical and theoretical approaches, Proceedings of the International Conference on Marine Research and Transportation (ICMRT), Ischia, Naples, Italy 28-30 June 2007.

[8]. Carlton, J.; Marine propeller and Propulsion Second Edition, Elsevier, USA, 2007.

[9]. Kuiper, G.; The Wageningen Propeller Series, MARIN publication 92-001, Netherland, May 1992.

[10]. Caterpillar; Engine specification Type 3408C 300-436 Kw and1800-2300 RPM, USA, 1997.
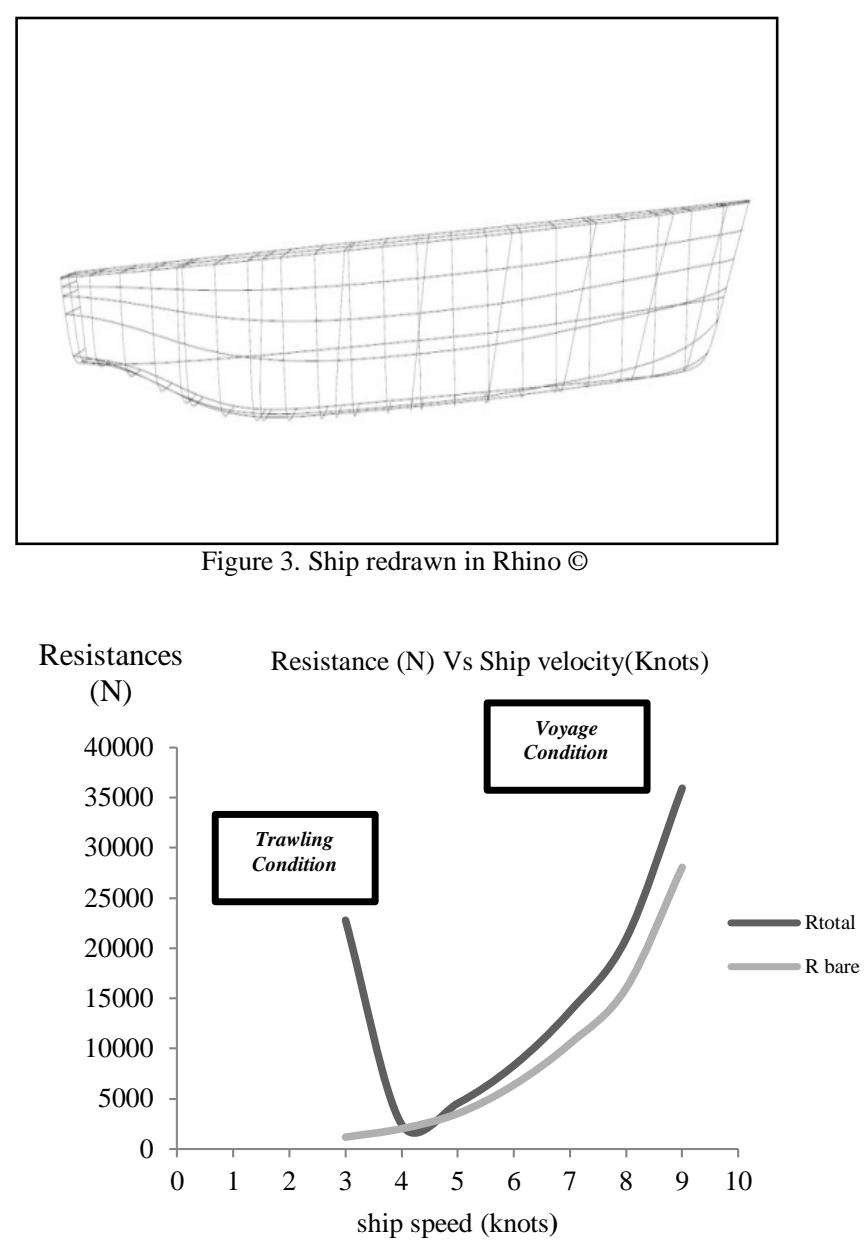

Figure 4. Resistances in trawling and voyage condition 

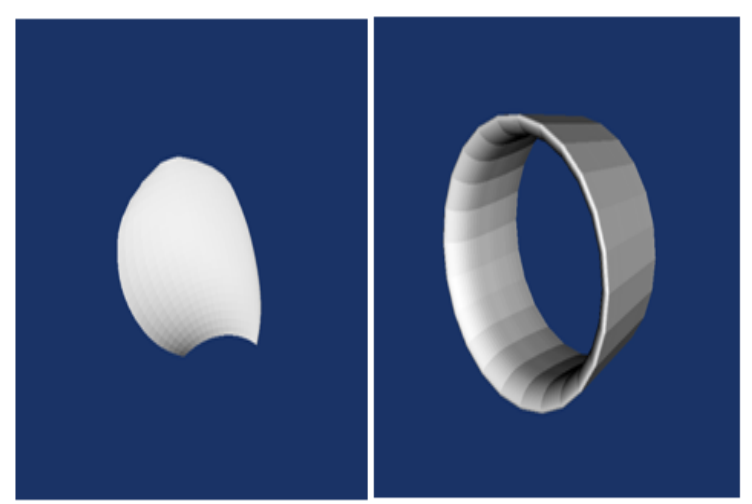

Figure 5. Propeller and duct meshing

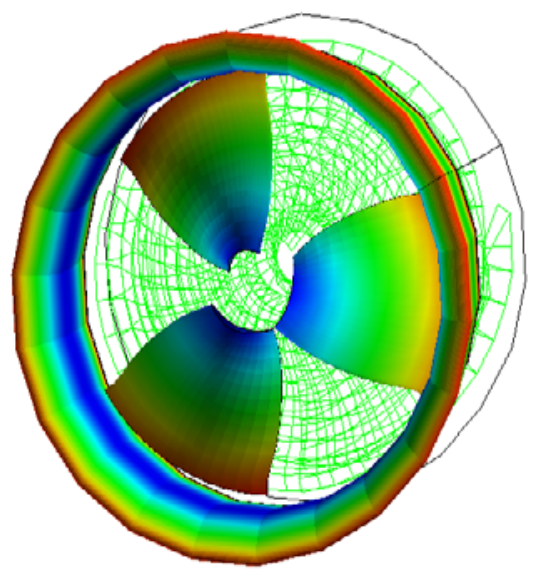

Figure 1. Propellers in center point relative to duct

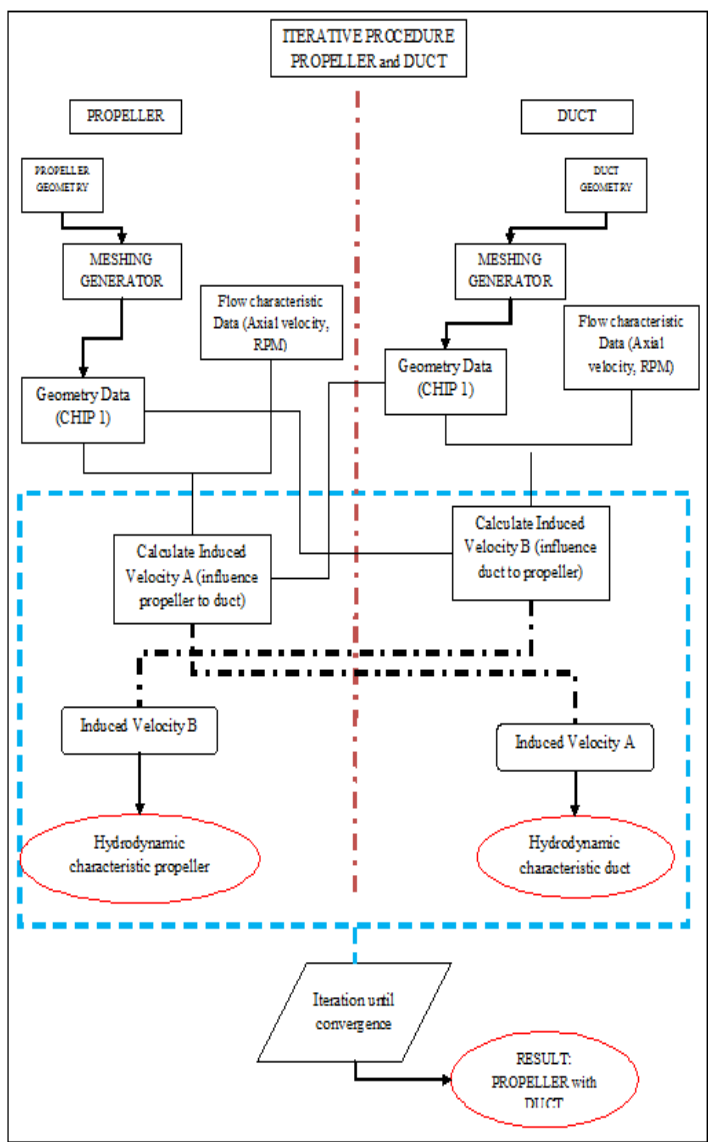

Figure 7. Iterative procedure for the propeller-duct interaction

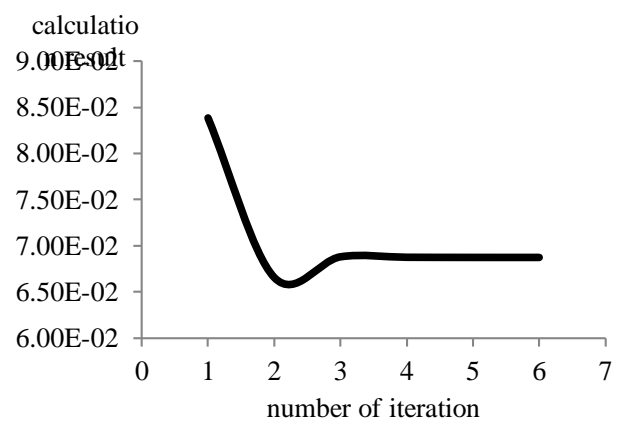

Figure 8. Example of calculation result versus number of iterations

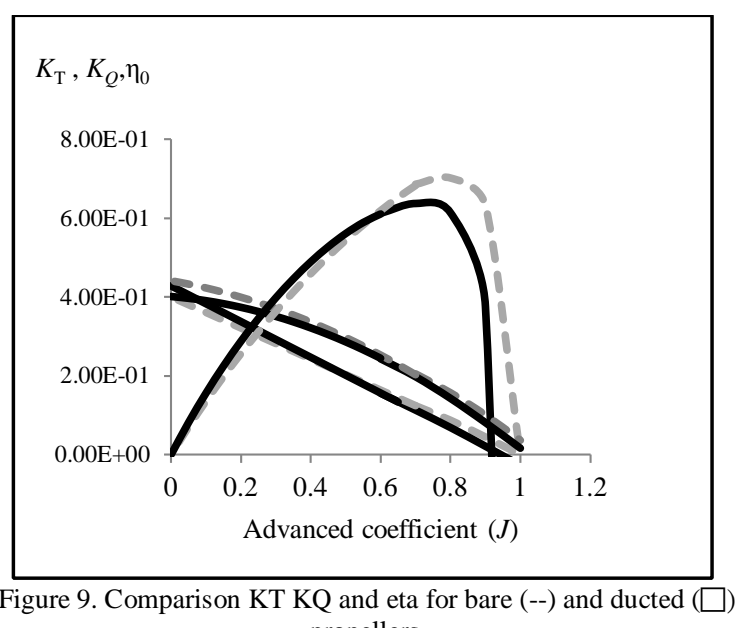

Figure 9. Comparison KT KQ and eta for bare (--) and ducted ( $\square$

$\mathrm{K}_{\mathrm{T}}$

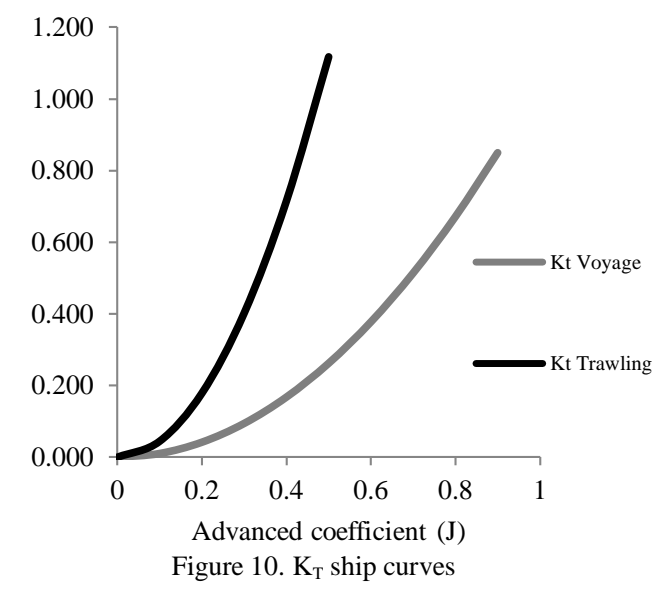

Coefficient

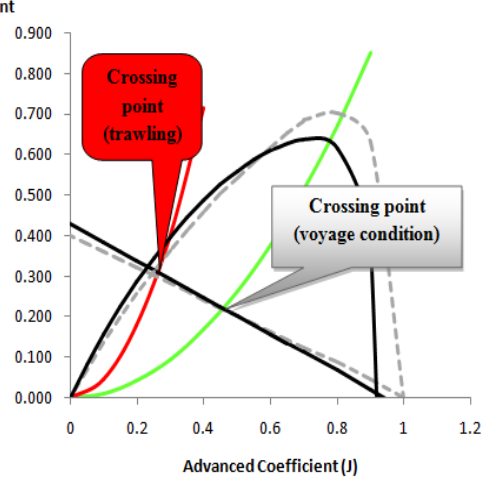

Figure 11. Matching or crossing point between propeller and ship load 


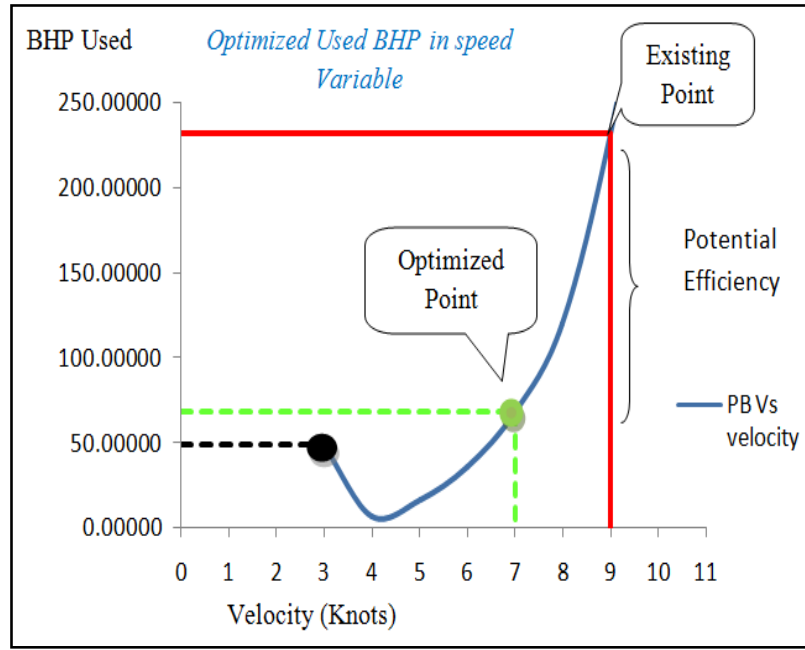

Figure 12. Illustrated the Optimization of BHP used in speed option

TABLE 1.

RESISTANCES IN TRAWLING AND VOYAGE CONDITION

\begin{tabular}{lcccc}
\hline \hline Condition & $\begin{array}{l}\text { Velocity } \\
(\text { Knots })\end{array}$ & $\begin{array}{l}\text { Rtrawl } \\
(\mathrm{kN})\end{array}$ & $\begin{array}{l}\text { Rbare } \\
(\mathrm{kN})\end{array}$ & $\begin{array}{l}\text { Rtotal } \\
(\mathrm{kN})\end{array}$ \\
\hline Trawling & 9 & 0 & 35.39 & 35.39 \\
Voyage & 3.5 & 21.6 & 1.2 & 22.8 \\
\hline \hline
\end{tabular}

TABLE 1.

SHIP EFFICIENCY RESULT CALCULATION

\begin{tabular}{ccccc}
\hline Condition & $\begin{array}{c}\text { Operational } \\
\text { Condition }\end{array}$ & $\begin{array}{c}\text { Fuel Consp } \\
\text { Kaplan(L) }\end{array}$ & $\begin{array}{c}\text { Fuel Consp B3-65 } \\
\text { (L) }\end{array}$ & $\begin{array}{c}\text { \% Save } \\
\text { using } \\
\text { Kaplan }\end{array}$ \\
\hline Voyage & $40 \%$ & 29952 & 34128 & 12.24 \\
Trawling & $60 \%$ & 30600 & 35280 & 13.27 \\
\hline Voyage & $50 \%$ & & & \\
Trawling & $50 \%$ & 38160 & 10.56 \\
\hline Voyage & $25 \%$ & 32220 & & \\
Trawling & $75 \%$ & & 32400 & 9.76 \\
\hline Voyage & $75 \%$ & 28980 & & \\
Trawling & $25 \%$ & & & \\
\hline
\end{tabular}

TABLE 1.

SHIP EFFICIENCY IN SPEED OPTIMIZE

\begin{tabular}{cccccc}
\hline \hline $\begin{array}{c}\text { Velocity } \\
\text { (Knots) }\end{array}$ & \%RPM & $\begin{array}{c}\text { \%BHP } \\
\text { used }\end{array}$ & $\begin{array}{c}\text { Fuel rate } \\
\text { (L/Hr) }\end{array}$ & $\begin{array}{c}\text { FC (L) } 1 \\
\text { month }\end{array}$ & $\begin{array}{c}\text { Saving } \\
\text { (\%) }\end{array}$ \\
\hline 9 & 83 & 48.3 & 41 & 29520 & 35.61 \\
7 & 72 & 28.7 & 26.4 & 19008 & \\
\hline \hline
\end{tabular}

